\title{
Processing and study of the wear and friction behaviour of discrete graded Cu hybrid composites
}

\author{
T RAM PRABHU* \\ RCMA (F\&F-FOL), Center for Military Airworthiness and Certification, Bangalore 560 093, India
}

MS received 2 March 2014

\begin{abstract}
Discrete functionally graded composites are the novel composites which have high potential in the brake friction material applications. In this paper, we have prepared discrete functional graded $\mathrm{Cu} / 10 \% \mathrm{SiC} /$ $\mathbf{2 0 \%}$ graphite(Gr)/10\% boron nitride (h-BN) hybrid composites by the layer stacking compaction and pressure sintering techniques. We have considered two types of composites based on h-BN particle sizes. The size ranges of h-BN used were 140-180 and 3-25 $\mu \mathrm{m}$. The friction and wear properties of the composites were evaluated in a laboratory scale brake inertial dynamometer at low $\left(5,10 \mathrm{~m} \mathrm{~s}^{-1}\right)$ and high sliding speeds $\left(30,35 \mathrm{~m} \mathrm{~s}^{-1}\right)$ and, high braking load $(2000 \mathrm{~N})$ conditions. In addition, we have performed microstructure characterization, density, hardness and flexural strength measurements. Wear surface morphology studies were also carried out using stereoscope and scanning electron microscope. Our experiments lead to the following important results: (1) the large size h-BN particle improves the densification of the hybridized composite layer and provides higher wear resistance and better braking performance at all sliding speeds, (2) the wear loss (by mass) and the stopping distance/time increase with sliding speeds due to the increase in the braking energy, (3) at low sliding speeds $(5,10 \mathrm{~m} \mathrm{~s}$ ), abrasive wear is the main wear mechanism, whereas many different wear mechanisms (delamination, oxidation, abrasive) are cooccuring at higher sliding speeds $\left(30,35 \mathrm{~m} \mathrm{~s}^{-1}\right)$, (4) the mechanical properties (flexural strength and surface hardness) of composites are not affected by the $\mathrm{h}-\mathrm{BN}$ particle size, (5) the incorporation of copper layer in the discrete layer structure deflects and arrests the crack at the copper/composite layer interface, thus improving the fracture resistance in addition to improving the bulk thermal conductivity.
\end{abstract}

Keywords. Functional graded composite; wear; friction; particle size; braking performance.

\section{Introduction}

Functional graded composites (FGC) are advanced composite materials which has a gradient in structure or composition across the section. This gradient brings the spatial variation in the physical, mechanical and thermal properties in the composites. Applications such as brake and clutch friction materials, gas turbine thermal barrier coatings, armour plates demand spatially varied properties in the components. For instance, brake friction materials demand contradictory properties of high wear resistance and friction at the contact surface, high thermal conductivity and toughness in the bulk material. These properties requirements may be met by designing the graded structure in the material. Most of studies on FGC are focussed on the development of a continuous gradient structure which has continuous variation in the properties across the gradient direction. ${ }^{1-3}$ However, the continuous gradient type FGC may not be suitable for brake friction materials because of the linear variation in the properties. Therefore, the discrete gradient is an ideal choice for the friction material because of the discrete change in the properties. Another advantage is that the preparation of the discrete gradient structure is relatively simple by the dry

\footnotetext{
*Author for correspondence (ramprabhu.t@gmail.com)
}

powder metallurgy processing. The drawbacks of this kind of structure are a sharp variation in the properties and the differential thermal behaviour of the layers. This may pose the problem to structure integrity. This problem can be circumvented by choosing the metallic layer similar to the composite matrix base which helps in minimizing the variation in the thermal behaviours between layers.

Numerous reports are available on the subject of the fabrication and wear studies of the $\mathrm{Cu} / \mathrm{SiC}$ composites. ${ }^{4-7}$ However, these wear studies are restricted to very low speed $\left(<2.5 \mathrm{~m} \mathrm{~s}^{-1}\right) /$ load $(<100 \mathrm{~N})$ conditions. Literature on wear studies at high sliding speed/load conditions are quite few. For instance, Prabhu et $a l^{8,9}$ have evaluated the wear behaviour of iron/SiC/Graphite hybrid composites at high sliding speeds $\left(25-35 \mathrm{~m} \mathrm{~s}^{-1}\right) /$ load $(1323 \mathrm{~N})$ in a laboratory scale brake inertial dynamometer.

Earlier Ramesha et l $^{10}$ studied the hybridization of $\mathrm{Cu} /$ $\mathrm{SiC}$ composites with graphite at different loads $(10-50 \mathrm{~N})$ and speeds $\left(0.3-1.2 \mathrm{~m} \mathrm{~s}^{-1}\right)$. They showed that the addition of graphite reduced the wear rate significantly. However, published studies on the dry sliding wear of $\mathrm{Cu}$ matrix hybrid composites are limited. Also, there are no wear studies on the discrete graded composites. Particularly, the discrete layer structure with hybridized composite layer is a novel idea for the brake friction material applications. In light of these, 
we have designed the discrete layer structure with copper layer in improving the wear and thermal properties of the $\mathrm{Cu}$ matrix hybrid composites.

Hexagonal structure boron nitride (h-BN) is a well known solid lubricant in the aeroengine coating applications. ${ }^{11}$ Besides, it possesses high thermal conductivity, high chemical stability, high thermal shock resistance and low thermal expansion. ${ }^{12}$ These properties make it a most preferable choice among solid lubricants. Unfortunately, the use of h-BN as a solid lubricant in the copper matrix composites have not been tried to date. Further, the size effects of h-BN in the friction and wear behaviour of hybridized composites are not explored yet. Hence, in our work, we have chosen h-BN and graphite solid lubricants to hybridize the composite layer.

Azreen et $a l^{13}$ reported that the optimum reinforcement content of $\mathrm{SiC}$ in the copper matrix is $10 \mathrm{vol} \%$ for the maximum hardness properties with not much sacrifice in the electrical/thermal conductivity for the sintering temperature of $850^{\circ} \mathrm{C}$. Hence, in our work, we have fixed the $\mathrm{SiC}$ reinforcement amount and sintering temperature to $10 \mathrm{vol} \%$ and $850^{\circ} \mathrm{C}$, respectively.

To the best of our knowledge, our report is the first report to explain the processing methodology of a discrete graded $\mathrm{Cu}$ matrix hybrid composites. Probably, it is one of the novel study explaining the wear and friciton properties of the composites at high sliding speed/load conditions.

\section{Experimental}

We have prepared two types of three-layer composites. The top layer was a composite layer. The composition of this layer was $\mathrm{Cu} / 10 \% \mathrm{SiC} / 20 \%$ graphite/10\%h-BN/1\% Sn (\% are in vol\%). The size ranges of the h-BN particles were varied between two types of composites. The small size h-BN particles were prepared by ball milling large size h-BN particles with a ball to charge ratio of $3: 1$ for $7 \mathrm{~h}$. The scanning electron micrograph of $\mathrm{SiC}$ and $\mathrm{h}-\mathrm{BN}$ particles are given in figures 1 and 2, respectively. The characteristics of powders are given in table 1 . The intermediate layer was a pure $\mathrm{Cu}$ layer. The variation of the copper content in the top two layers creates a discrete gradient in the composites. The bottom layer was a steel cup in which powders were stacked to form layers. The bottom layer provides the support to composite from any catastrophic failure arising from sudden loading. The thicknesses of the steel, copper and composite layers were $1,4 \pm 0.5$ and $3.5 \pm 0.5 \mathrm{~mm}$, respectively. The macrograph of the layers in the composite is shown in figure 3. The layers were compacted with a pressure of 255 $\mathrm{MPa}$ at room temperature. The composites were sintered using a two-stage pressure sintering process under the dry hydrogen atmosphere for $3 \mathrm{~h}$. The sintering temperatures and pressure were $250^{\circ} \mathrm{C}, 850^{\circ} \mathrm{C}$ and $5 \mathrm{MPa}$, respectively. To facilitate the liquid phase sintering and remove the binders, composites were held at $250^{\circ} \mathrm{C}$. The sintered composites were repressed at a pressure of $190 \mathrm{MPa}$ for improving the densification and relieve the internal stresses.

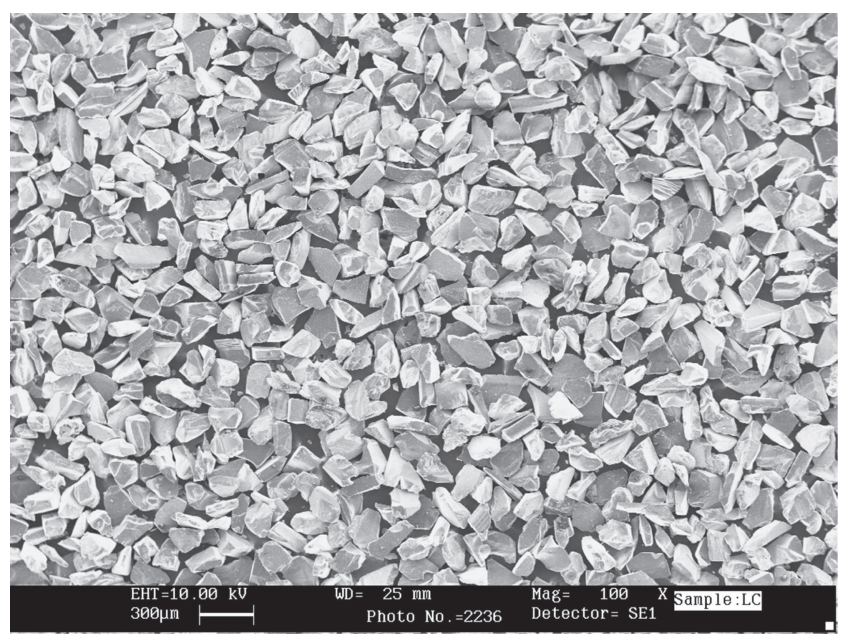

Figure 1. SEM image of $\mathrm{SiC}$ particles (size range: $180-210 \mu \mathrm{m}$ ).

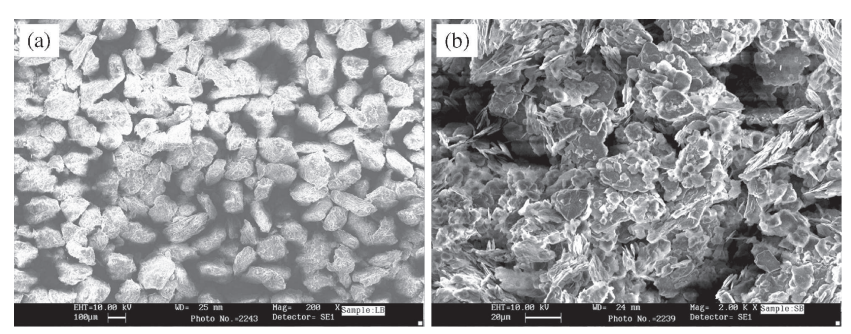

Figure 2. SEM image of (a) large size (size range: $140-180 \mu \mathrm{m}$ ) and (b) small size (size range: 7-25 $\mu \mathrm{m}$ ) boron nitride particles.

The powders were screened in the sieves for determining the size ranges. Particularly, the boron nitride and SiC particle sizes were measured from the scanning electron micrograph with an aid of ImageJ software (NIH). The density of the composites was evaluated using the Archimedes principle. The microstructure of the composites was examined using stereo (SEIWA) and optical (Nikon Epiphot) microscopes. The wear and friction tests were carried out in a laboratory scale dynamometer. The schematic of the dynamometer and its operation, the sample preparation, the burnishing procedure of the samples, the countersurface and the testing procedure were given elsewhere. ${ }^{8,9}$ The friction and wear testing parameters are given in table 2 . Wear experiments were conducted in air at a room temperature of $25^{\circ} \mathrm{C}$ and the relative humidity of $40-60 \%$. The wear surfaces were analyzed in a scanning electron microscope (FEI-SIRION SEM) to identify the wear mechanisms. The flexural strength of the composites were measured in a three-point bend set-up. The set up fixtures were assembled in the universal testing machine (TIRA 2820S). The testing was performed at a cross head speed of $1.67 \times 10^{-5} \mathrm{~m} \mathrm{~s}^{-1}$. The dimensions of a sample and the load span length were $60 \times 15 \times 8 \mathrm{~mm}$ and $50 \mathrm{~mm}$, respectively. The hardness of the composites was measured in a Brinell scale. A steel ball of $10 \mathrm{~mm}$ diameter and a load of $10 \mathrm{~kg}$ were used to measure the surface, layer and layer interface hardness. 
Table 1. Properties of powders $(*,+$ indicate small and large size reinforcement, respectively).

\begin{tabular}{lcccccc}
\hline Powder & $\mathrm{SiC}$ & h-BN & Graphite & $\mathrm{BaSO}_{4}$ & $\mathrm{Sn}$ & $\mathrm{Cu}$ \\
\hline Mean size $(\mu \mathrm{m})$ & 195 & $16^{*}, 160^{+}$ & 125 & 75 & 50 & 75 \\
Purity $(\%)$ & 95 & 90 & 95 & 95 & 99 & 99 \\
Grade & $\alpha-\mathrm{SiC}$ & Hexagonal & Natural & IS 64-1992 & Atomized & Electrolytic \\
& $(6-\mathrm{H})$ & BN & (flaky) & Gr:2, Type I & & \\
\hline
\end{tabular}

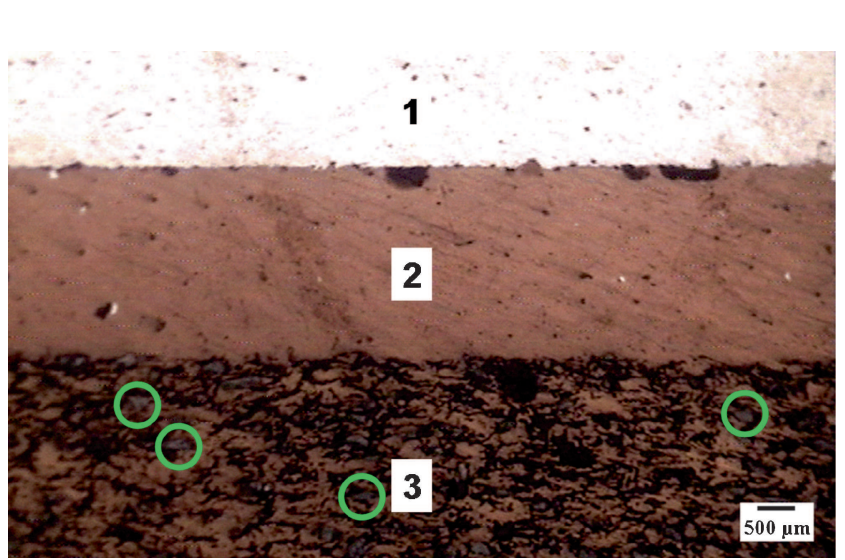

Figure 3. Macrograph of the layer structure in the Hybrid-A $(\mathrm{Cu} / \mathrm{SiC} / \mathrm{Gr} / \mathrm{h}-\mathrm{BN})$ composite, (1) steel layer, (2) pure copper layer and (3) composite layer. Circle indicates the uniform distribution of the $\mathrm{SiC}$ particles.

Table 2. Wear testing parameters of dry sliding wear and friction tests.

\begin{tabular}{lcccc}
\hline $\begin{array}{l}\text { Sliding } \\
\text { speed } \\
\left(\mathrm{m} \mathrm{s}^{-1}\right)\end{array}$ & $\begin{array}{c}\text { Load } \\
(\mathrm{N})\end{array}$ & $\begin{array}{c}\text { Braking } \\
\text { energy } \\
(\mathrm{kJ})\end{array}$ & $\begin{array}{c}\text { No. of braking } \\
\text { stops }\end{array}$ & $\begin{array}{c}\text { Moment of inertia of } \\
\text { the flywheel } \\
\left(\mathrm{N} \mathrm{m} \mathrm{s}^{-2}\right)\end{array}$ \\
\hline 5 & 2000 & 8 & 20 & 40 \\
10 & 2000 & 31 & 20 & 40 \\
30 & 2000 & 282 & 20 & 40 \\
35 & 2000 & 385 & 20 & 40 \\
\hline
\end{tabular}

\section{Results and discussion}

\subsection{Porosity}

The density and $\%$ porosity of the composites are given in table 3. The density and densification of Hybrid-A composite is slightly higher than that of Hybrid-B composite. It is quite logical to presume that the copper layer sintered in a similar fashion in both the composites because the structure, the composition, the size of the $\mathrm{Cu}$ layer and the sintering practice are exactly same. The layer microstructures study (described in the next section) excludes the chance of porosity arising from interlayer bonding regions. Therefore, the only existing difference between composites, the particle size range of h-BN, may probably related to the improved densification of the composite layer. Small size particles show high tendency to the agglomeration due to high surface energy, as evident from the SEM image. These particles are heavy deformed during ball milling leading to irregular shapes. Further, the size range of the small size particles was narrow. These three factors probably lead to slightly lower density and densification in the Hybrid-B composites.

\subsection{Microstructure}

The microstructure of a Hybrid-A composite is shown in figure 4. The layer structure is clearly evident in the composite. The bonding between layers is smooth and free from defects such as voids, delamination. The interface between top two layers is well combined because the composite matrix is similar to metallic layer. The microstructure of a composite layer (as in figure 5) shows that the distributions of $\mathrm{SiC}$ (light grey colour) and solid lubricants (graphite and h-BN) particles (dark shadow regions) are uniform with no evidence of porosity cluster zones. Further, the high magnification image of the composite layer (as in figure 6a) shows the sound quality interface of particles and matrix without any debonded regions. The microstructure of a bottom steel layer (as given in figure 6b) contains predominately ferrite with small amount of pearlite phases. It is important to note that there is no diffusion of particles to the copper layer. This ensures the thermal and deformation properties of the copper layer unaffected. From the microstructure examinations, it can be concluded that the discrete layers in the composite are well sintered with free of interfacial defects and the distribution of abrasive and solid lubricants particles are homogeneously distributed in the top composite layer.

\subsection{Wear and friction behaviour}

The wear rate is the one of the important parameter which decides the life of the brake friction material. Therefore, it is important to design a brake friction material with least wear loss. The wear rate of the composites is given in figure 7 . The wear rate of the composites reduces with sliding speeds up to $30 \mathrm{~m} \mathrm{~s}^{-1}$. The prevailing wear mechanisms at a particular sliding speed decide the wear rate. As seen in figures $8 \mathrm{a}$ and $9 \mathrm{a}$, the wear surface of the composite tested at $10 \mathrm{~m} \mathrm{~s}^{-1}$ shows mainly grooves running parallel to the sliding direction. It confirms the dominance of abrasive wear. The grooves are caused by two probable ways: (1) countersurface asperities and (2) third body wear. The third body wear arises due to the removed abrasive particles from 
Table 3. Properties of $\mathrm{Cu} / \mathrm{SiC} / \mathrm{Gr} / \mathrm{h}-\mathrm{BN}$ hybrid composites.

\begin{tabular}{lccccc}
\hline Designation & $\begin{array}{c}\text { Flexural } \\
\text { strength (MPa) }\end{array}$ & $\begin{array}{c}\text { Surface } \\
\text { hardness (BHN) }\end{array}$ & $\begin{array}{c}\text { Theoretical } \\
\text { density }\left(\mathrm{g} \mathrm{cm}^{-3}\right)\end{array}$ & $\begin{array}{c}\text { Measured } \\
\text { density }\left(\mathrm{g} \mathrm{cm}^{-3}\right)\end{array}$ & $\begin{array}{c}\% \text { Porosity } \\
\text { (calculated) }\end{array}$ \\
\hline Hybrid-A & 126 & $62 \pm 3$ & 7.46 & 7.07 & 5.24 \\
Hybrid-B & 122 & $52 \pm 2$ & 7.46 & 6.82 & 8.59 \\
\hline
\end{tabular}
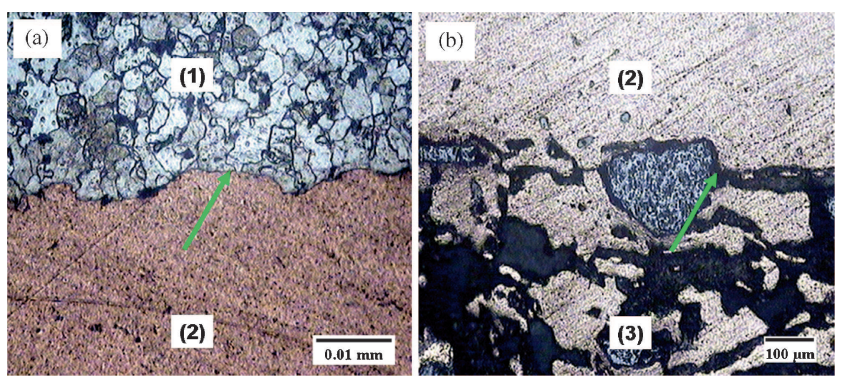

Figure 4. Layer microstructure of the Hybrid-A $(\mathrm{Cu} / \mathrm{SiC} / \mathrm{Gr} / \mathrm{h}-$ BN) composite, (a) steel (1) and copper (2) layers, (b) copper (2) and composite (3) layers. Arrow indicates the defect-free, continuous interface between layers.

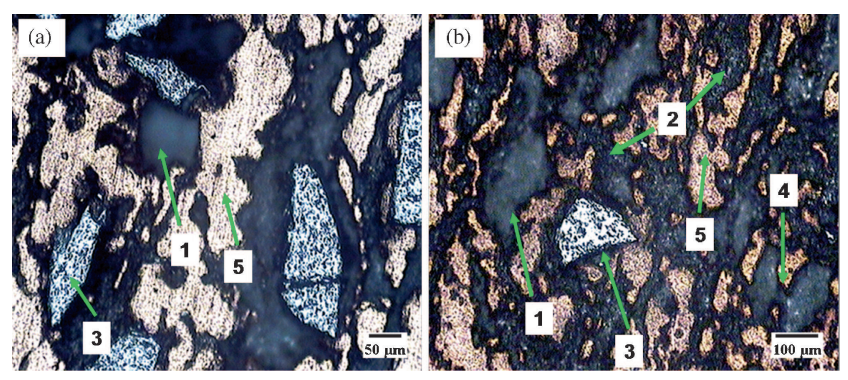

Figure 5. Microstructure of the composite layer in the HybridA $(\mathrm{Cu} / \mathrm{SiC} / \mathrm{Gr} / \mathrm{h}-\mathrm{BN})$ composite: (1) graphite, (2) boron nitride, (3) $\mathrm{SiC},(4)$ graphite particle flow and (5) copper matrix.

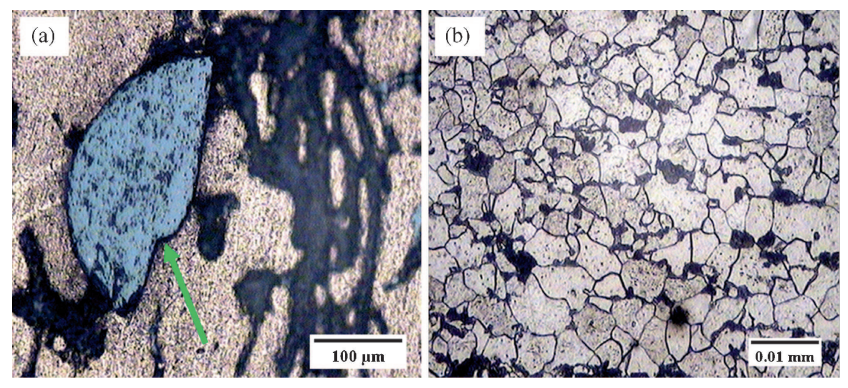

Figure 6. (a) High magnification image of interface of SiC particles and copper matrix showing uniform, continuous interface free from voids, cracks or other defects in the composite and (b) microstructure of the steel layer showing small amount of pearlite dispersed in the ferrite matrix.

the surface of the composites. The observation of protruded $\mathrm{SiC}$ particles (as seen in figure 9b) supports the occurrence of third body wear. There is no observation of oxide scale

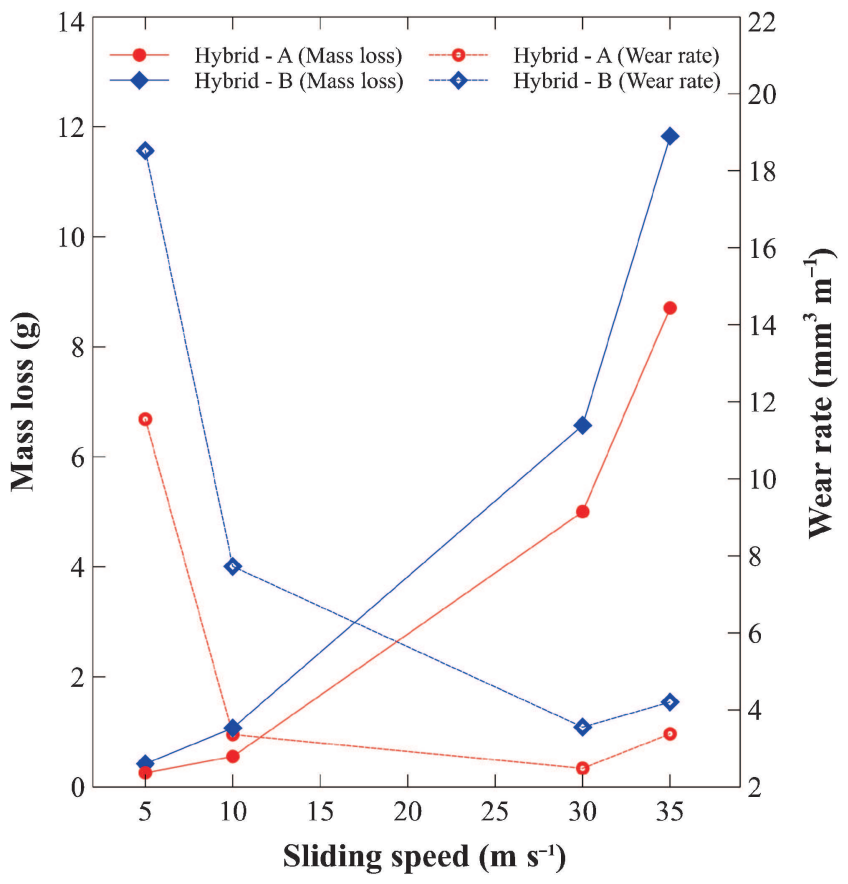

Figure 7. Wear rate and mass loss of the $\mathrm{Cu} / \mathrm{SiC} / \mathrm{Gr} / \mathrm{h}-\mathrm{BN}$ composites.
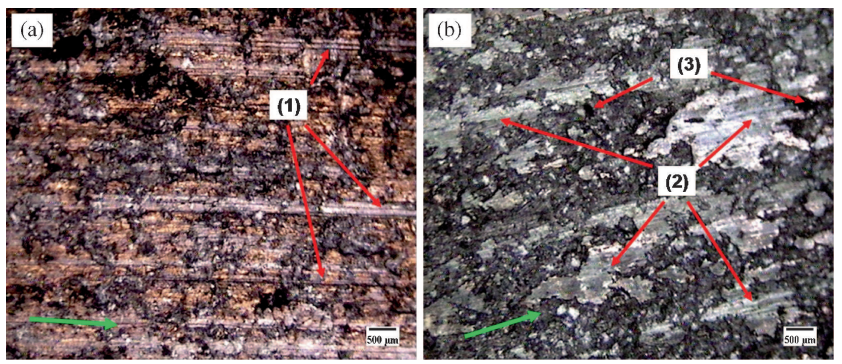

Figure 8. Macrographs of the Hybrid-A composite tested at (a) $10 \mathrm{~m} \mathrm{~s}^{-1}$, (b) $30 \mathrm{~m} \mathrm{~s}^{-1}$ : (1) groove lines, (2) oxide scales and (3) particulate pull-out regions. Arrow indicates the sliding direction.

in the macrograph of the same composite, as observed in figure 8a. It implies that the frictional surface heating does not oxide or soften the composite at low sliding speeds (5$10 \mathrm{~m} \mathrm{~s}^{-1}$ ). Therefore, the wear rate is completely controlled by the third body wear. Comparing the composites, the wear resistance of a Hybrid-A composite is marginally better than that of a Hybrid-B composite. The small size h-BN covers more surface area than the large size $\mathrm{h}-\mathrm{BN}$ for the equal 

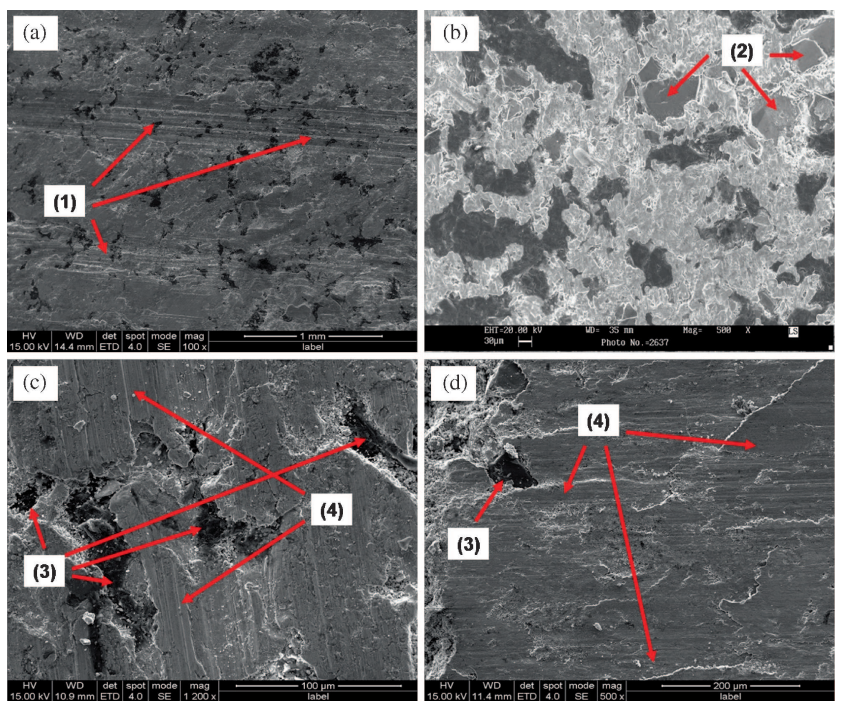

Figure 9. SEM images of the Hybrid-A composite tested at (a) $10 \mathrm{~m} \mathrm{~s}^{-1}$, (b) $30 \mathrm{~m} \mathrm{~s}^{-1}$, Hybrid-B composite tested at (c) $10 \mathrm{~m} \mathrm{~s}^{-1}$, (d) $30 \mathrm{~m} \mathrm{~s}^{-1}$ : (1) groove lines, (2) protruded SiC particles on the surface, (3) particulate pull-out regions and (4) tribolayer. Arrow indicates the sliding direction.

volume fractions. The low shear strength boron nitride gets easily scratched and removed by asperities of counter surface and third body abrasives. The removal of h-BN is higher in the small size h-BN reinforced composite (Hybrid-B). Thus the wear rate of the Hybrid-B composite is higher than the Hybrid-A at low sliding speeds $\left(5-10 \mathrm{~m} \mathrm{~s}^{-1}\right)$.

At higher sliding speeds $\left(30-35 \mathrm{~m} \mathrm{~s}^{-1}\right)$, the effect of frictional heating is clearly evident from the mass loss. The frictional temperature increases with the sliding speed or braking energy. The rise in frictional temperature oxidizes the constituents in the composites. Particularly, the matrix gets oxidized significantly. Further, the increase in the surface temperature enhances the diffusion activity between the contact surfaces. The retained residual compressive stresses at the particle/matrix interface after repressing gets relieved. The increase in dislocation activity by climb and grain growth processes degrade the mechanical strength properties. The application of braking force at higher sliding speed activates the particle/matrix delamination during rubbing. Thus causes significant mass loss of the composites. The conversion of mass loss to volumetric wear rate indicates that the wear rate increases from 30 to $35 \mathrm{~m} \mathrm{~s}^{-1}$. It implies that the critical sliding speed at which the wear rate is at minimum or in other words the rate of removal and replenishment of a tribolayer are balanced at $30 \mathrm{~m} \mathrm{~s}^{-1}$. Beyond the speed, the oxide scale thickness increases by increasing oxidation rate. Therefore, the cracking of scale occurs faster. In addition, the material softening due to increasing friction temperature weakens the particle/matrix interface resulting huge mass loss. It is important to note that the increase of sliding speed helps in forming lubricating oxides and tribolayer at the wearing surface and controls the wear per unit

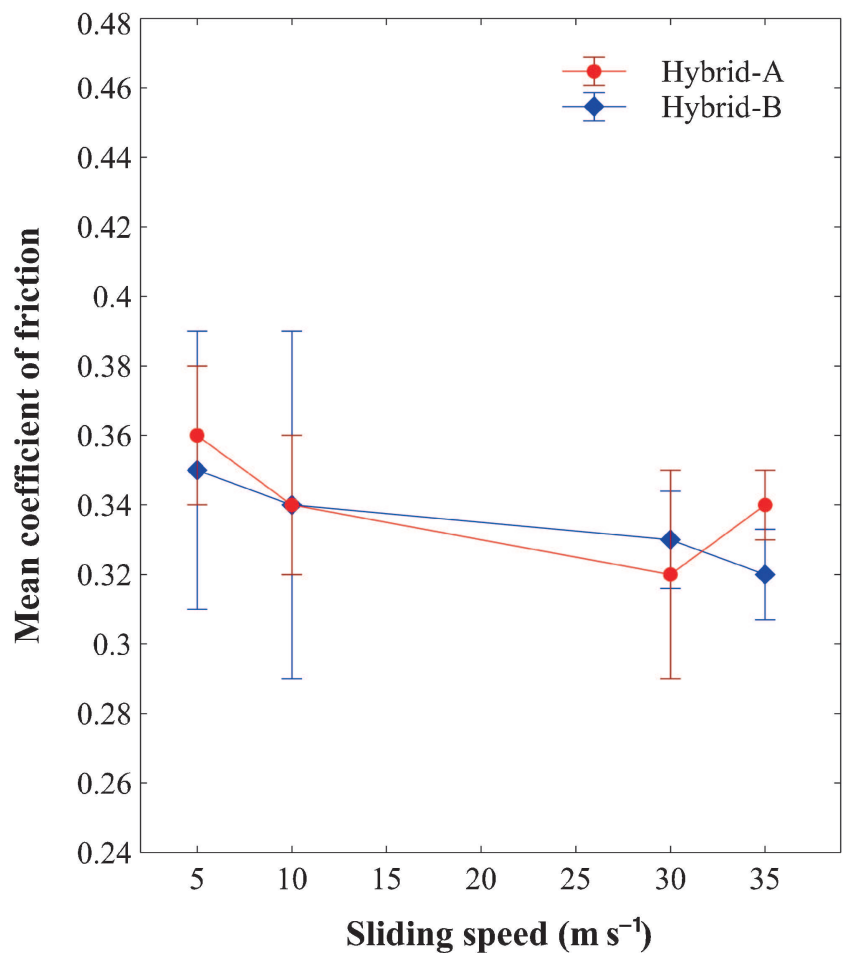

Figure 10. Variation of mean coefficient of friction with sliding speeds for the $\mathrm{Cu} / \mathrm{SiC} / \mathrm{Gr} / \mathrm{h}-\mathrm{BN}$ composites.

sliding distance upto the critical speed. The macrograph and SEM image of the composite tested at $30 \mathrm{~m} \mathrm{~s}^{-1}$, as shown in figures $8 \mathrm{~b}, 9 \mathrm{c}$ and $\mathrm{d}$ confirms the oxidation and delamination wear mechanisms. The SEM images further show clearly the existence of the tribolayer. Comparing between the composites under study, the Hybrid-A performs marginally better than the Hybrid-B composites. The same explanation of higher h-BN removal holds true hereto.

The change of friction coefficient with sliding speeds is given in figure 10. The friction coefficient decreases with sliding speed. The variation in the friction coefficient at low sliding speeds $\left(5,10 \mathrm{~m} \mathrm{~s}^{-1}\right)$ are associated mainly with the third body wear and the absence of the lubricating tribolayer at the wearing surfaces. The increase in sliding speed/brake energy causes the oxidation of the composite. The solid lubricants, e.g., h-BN, graphite embedded in the surface easily get squeezed out due to the higher intensity of subsurface deformation rate at higher sliding speeds. These lubricants mix with oxides and form the tribolayer on the composite surface which controls the friction. In addition, the intensity of the third body wear is also reduced due to the benefical effects of tribolayer. Thus, the tribolayer plays a key role in minimizing the variation in the friction with increasing sliding speeds. The stopping distance or the stopping time is one of the important braking parameters which evaluate the efficacy of the brake friction materials. The variations of the stopping distance and the stopping time with sliding speeds are given in figures 11 and 12, respectively. The friction coefficient or torque generated during braking decides both 


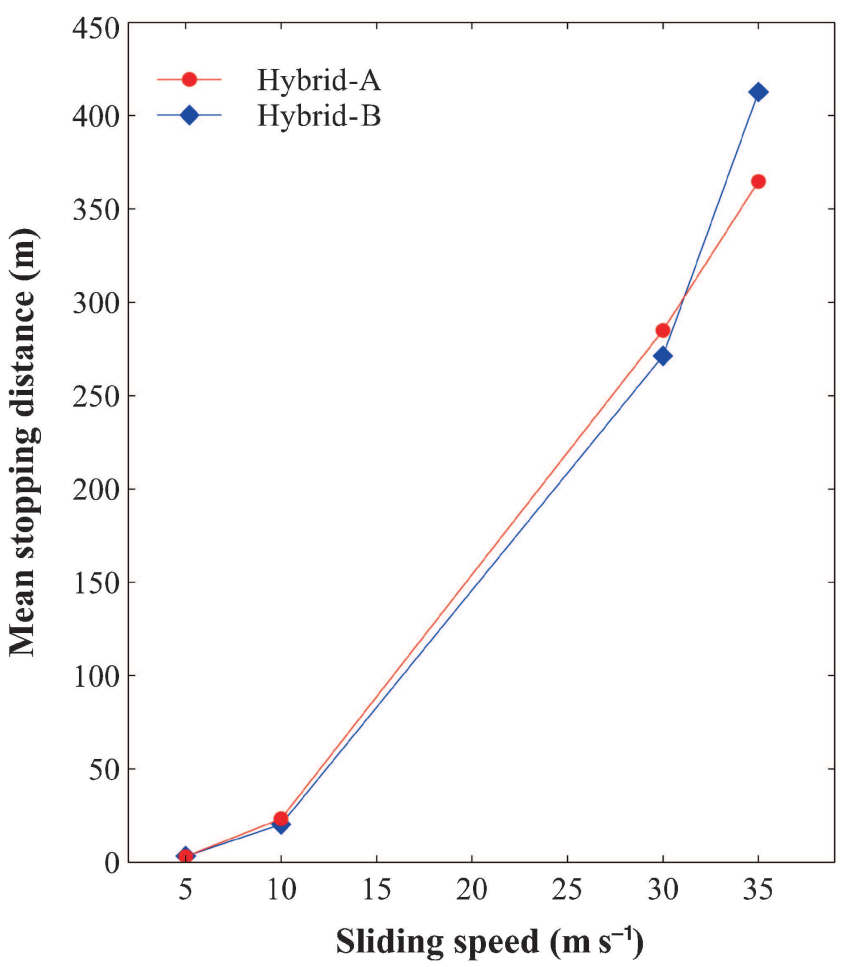

Figure 11. Variation of mean stopping distance with sliding speeds for the $\mathrm{Cu} / \mathrm{SiC} / \mathrm{Gr} / \mathrm{h}-\mathrm{BN}$ composites.

the stopping distance and the stopping time of a moving body. The friction coefficient has an indirect relation with the stopping distance/time. Thus, the trend of the friction coefficient is quite opposite to that of the stopping distance/time. The stopping distance is related to the stopping time by Newton's laws. Thus, it is obvious that the trends of the stopping distance and the stopping time with the sliding speed are similar. Between the hybrid composites, the stopping distances/times are almost similar up to $30 \mathrm{~m} \mathrm{~s}^{-1}$. At $35 \mathrm{~m} \mathrm{~s}^{-1}$, the Hybrid-A provides shorter stopping distance/ time than the Hybrid-B. It may be probably due to the better coverage of tribolayer. The increase in friction decreases the stopping distance/time. At the same time, the increase in friction increases the wear loss. Therefore, the friction should be in a optimum level to balance both the wear loss and the stopping distance. In light of these factors, Hybrid-A composite shows higher wear resistance and better braking performance (shorter stopping distance, higher $\mathrm{CoF}$ ) than the Hybrid-B composite.

\subsection{Mechanical properties}

The flexural properties and surface hardness of the composites are given in table 3. The flexural strength of a Hybrid-A composite is marginally higher than that of a Hybrid-B composite. The better flexural strength properties of a Hybrid-A composite is attributed to its lower porosity content. The section view of a flexural tested sample is given in figure 13 .

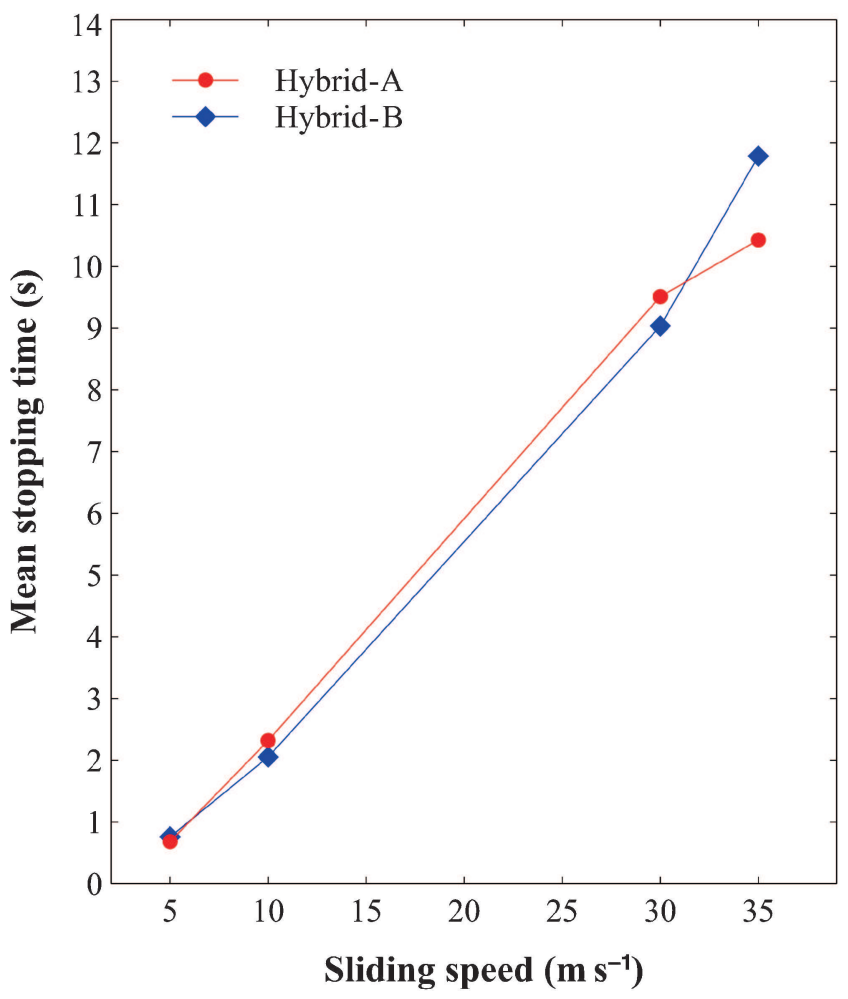

Figure 12. Variation of mean stopping time with sliding speeds for the $\mathrm{Cu} / \mathrm{SiC} / \mathrm{Gr} / \mathrm{h}-\mathrm{BN}$ composites.

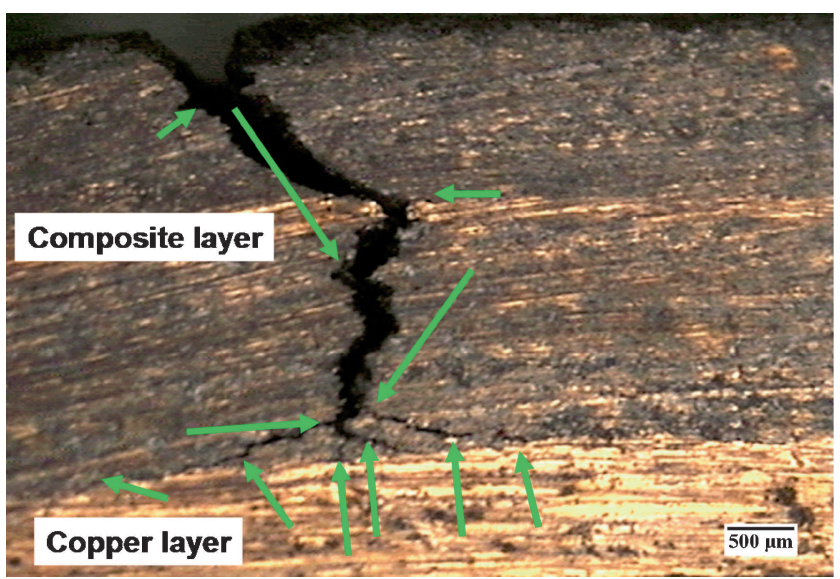

Figure 13. Sectional view of the layers in the flexural tested Hybrid-A composite. Arrow indicates the branching and deflection of the crack inside the composite layer and at the composite/copper interlayer.

The crack deflection and branching are observed at the junction between the composite and the $\mathrm{Cu}$ layer. It is obvious that the crack initiates in the composite layer because of the tensile loading. As the crack proceeds the inner layer, the tip of a crack blunts by the enlargement of the plastic zone size. The ductile copper layer enlarges the plastic zone size. The resultant crack shielding improves the fracture resistance of the composites. 


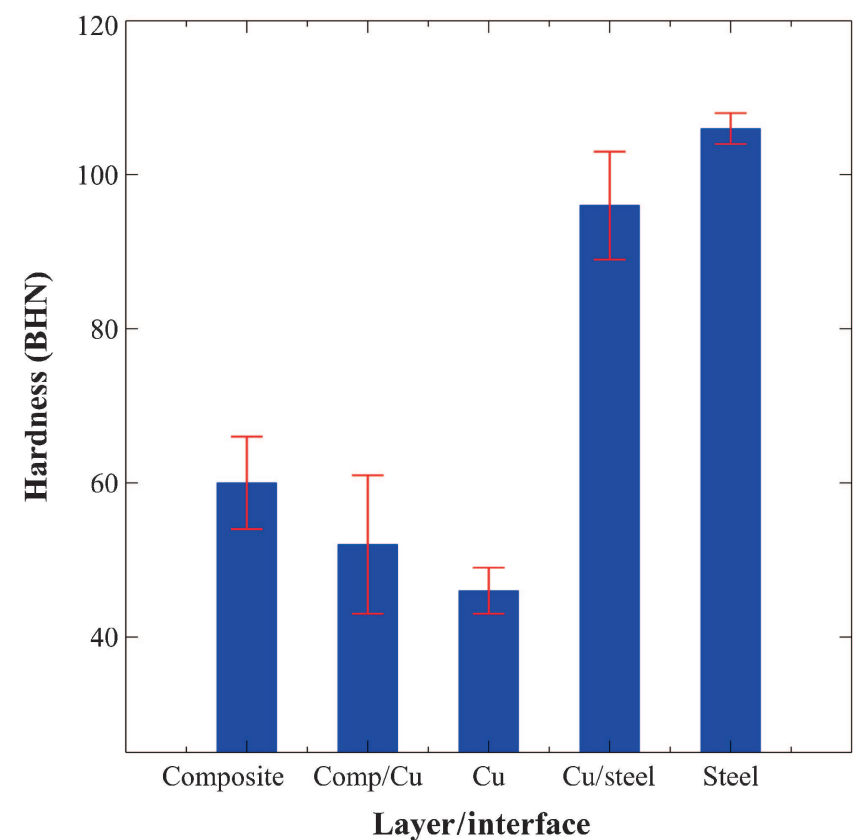

Figure 14. Layer and layer interface hardness of the Hybrid-A composite.

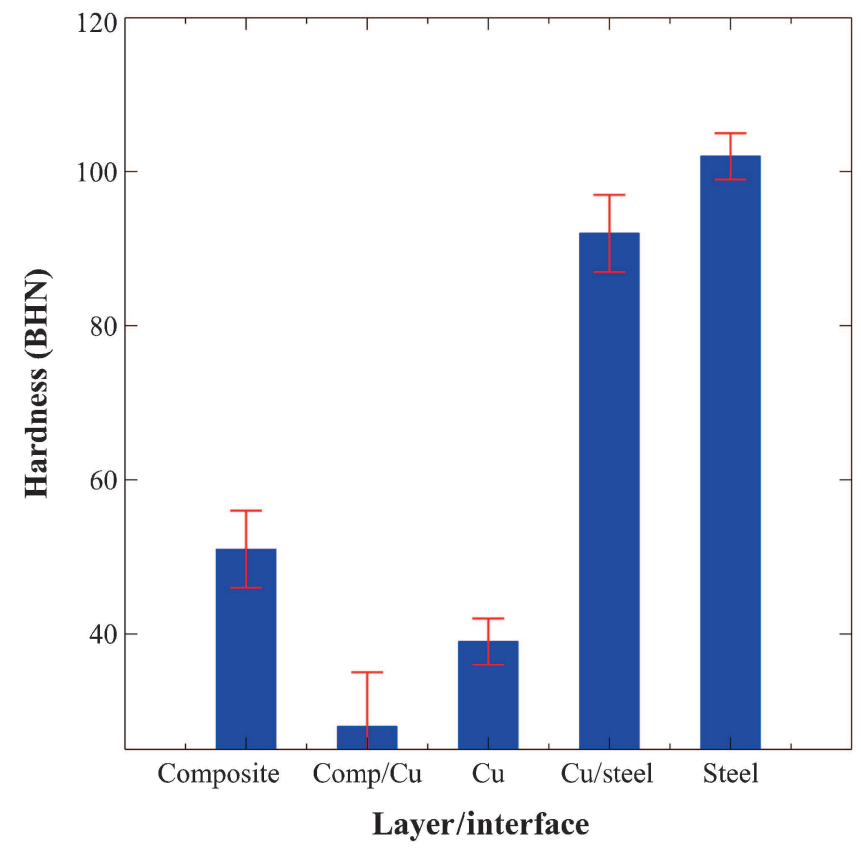

Figure 15. Layer and layer interface hardness of the Hybrid-B composite.

The surface hardness of the composites are similar indicating that the role of h-BN particle size is negligible. The sectional hardness of the composites is given in figures 14 and 15. The layer hardness of the composites shows that the negative gradient of the hardness exists from the composite to copper layer. Thus results the toughness of the composite to increase from the composite to copper layer. The layer interface hardness of a Hybrid-A composite lies between the either side layer hardness whereas for the Hybrid-B composite, the hardness of a composite/Cu layer interface is slightly lower than the copper layer hardness indicating the slightly inferior quality of interlayer bonding. Perhaps, this may explain the poor wear resistance of the Hybrid-B composite especially at higher sliding speeds $\left(30,35 \mathrm{~m} \mathrm{~s}^{-1}\right)$ due to the reduction of the bulk thermal conductivity.

\section{Conclusion}

We have developed successfully the discrete graded structure in the $\mathrm{Cu}$ hybrid composites using layer stacking compaction and pressure sintering techniques. We have studied the wear, friction and mechanical properties of the composites. Our study leads to following important results:

- The microstructure examination of the composites confirms the presence of three layers: (1) top hybridized composite layer with uniform distribution of $\mathrm{SiC}$ and solid lubricants (graphite, h-BN), (2) intermediate layer of pure copper and (3) bottom steel layer. The interlayer bonding and the particle/matrix interfaces in the composite are of sound quality.

$\downarrow$ The large size h-BN particle improves the densification of the hybridized composite layer and provides higher wear resistance and better braking performance at all sliding speeds. The comparatively poor wear resistance of a Hybrid-B composite are related to relatively inferior bonding between layers as confirmed by hardness studies.

- The increase in braking energy enhances the wear loss (by mass), the stopping distance/time with sliding speeds.

\ The macrographs and SEM studies show that abrasive wear is the principle wear mechanism at low sliding speeds $\left(5,10 \mathrm{~m} \mathrm{~s}^{-1}\right)$, whereas the joint operation of mixed mode wear mechanisms (delamination, oxidation, abrasive) are found at high sliding speeds $\left(30,35 \mathrm{~m} \mathrm{~s}^{-1}\right)$.

- The mechanical properties (flexural strength and surface hardness) of composites are not affected by the variation of h-BN particle sizes. The incorporation of copper layer in the discrete structure deflects and arrests the crack at the copper layer. Thus, the soft copper layer in the discrete layer composite is beneficial in improving the fracture resistance in addition to improving the bulk thermal conductivity.

\section{Acknowledgements}

I thank Dr K Tamilmani, Director General (Aeronautical) \& Chief Executive (CEMILAC), DRDO and Mr G Gouda, Group Director (Propulsion) for their constant encouragement and support. I also acknowledge the material and testing support rendered by HAL. 


\section{References}

1. Melgarejo Z H, Suarez O M and Sridharan K 2006 Scr. Mater. 5595

2. Nai S M L, Gupta M and Lim C Y H 2003 Compos. Sci. Technol. 631895

3. Vieira A C, Sequeira P D, Gomes J R and Rocha L A 2009 Wear 267585

4. Dhokey N B and Paretkar R K 2008 Wear 265117

5. Kennedy F E, Balbahadur A C and Lashmore D S 1997 Wear 203-204 715
6. Sapate S G, Uttarwar A, Rathod R C and Paretkar R K 2009 Mater. Des. 30376

7. Tjong S C and Lau K C 2000 Mater. Lett. 43274

8. Prabhu T R, Varma V K and Vedantam S 2014 Wear 3091

9. Prabhu T R, Varma V K and Vedantam S 2014 Wear 309247

10. Ramesha C S, Ahmed R N, Mujeebub M A and Abdullahc MZ 2009 Mater. Des. 301957

11. Cao Y, Du L, Huang C, Liu W and Zhang W 2011 Appl. Surf. Sci. 25710195

12. Seghi S, Fabio B and Economy J 2004 Carbon 423043

13. Azreena A R F, Sutjipto G E and Adesta E Y T 2011 Adv. Mater. Res. 264-265 748 